\title{
Slow, lazy and stupid
}

\author{
Oikkonen Elena
}

This is a Final draft version of a publication

published by Edward Elgar Publishing

in How to Become an Entrepreneurship Educator

DOI: $10.4337 / 9781789900033.00024$

Copyright of the original publication: (C) The Editor and Contributors Severally 2020

Please cite the publication as follows:

Oikkonen, E. (2020). "Slow, lazy and stupid". In How to Become an Entrepreneurship Educator. Cheltenham, UK: Edward Elgar Publishing. doi: https://doi.org/10.4337/9781789900033.00024

This is a draft chapter. The final version is available in How to Become an Entrepreneurship Educator edited by Colin Jones, published in 2021, Edward Elgar Publishing Ltd. https://doi.org/10.4337/9781789900033.00024 The material cannot be used for any other purpose without further permission of the publisher, and is for private use only.

This is a parallel published version of an original publication. This version can differ from the original published article. 


\section{Associate professor Elena Oikkonen}

\section{Slow, lazy and stupid}

\section{MY TEACHING PHILOSOPHY}

I could not find a reference to my teaching philosophy, slow, lazy and stupid, but the idea is that I as an educator try to do my best to activate the participants (teachers in teacher-training sessions and students in university course) in order to enable them to present ideas, make choices, plan, set goals and, finally, check whether something was learned and if so, how and why.

I try to act as a facilitator, present the main idea and goal if there is one and then let the participants to be the active problem-solvers. That means, I try to give them time (with me being slow in my actions) to think and determine what to do next, letting them be active in the learning and learning process, relying on me only if they have something to ask. Even then, I act only as a knowledge resource but do not give them any answers, rather asking questions as to how they might proceed, for example in what they are doing and in what ways they are going to meet the goal.

Speaking personally, it is not always an easy process to just follow, letting your students 'fail'; but I think sometimes it also hurts to learn through trial and error. This approach normally is not the easiest way out and not the shortest way of learning, but I'm quite convinced that once you have learned something in this kind of a process, you remember that for the rest of your life.

MY CONTEXT 
Since 2000, I have been working at Lappeenranta University of Technology (LUT), Finland. In the beginning, I ran teacher-training projects concerning primary and secondary level teachers' ICT skills, but for more than the last 15 years the topic has been entrepreneurship and entrepreneurship education. So, it can be said that because of these different projects I became an educator.

Nowadays, I run many national and international projects where I guide teachers representing all education levels (from primary level to university) on how to put entrepreneurship education into practice. This has been very interesting and challenging as teachers have very different backgrounds, their understanding concerning entrepreneurship and entrepreneurship education varies a lot, and there are great differences in how to put $\mathrm{EE}$ into action if you work with young pupils or university students.

In addition to teacher training, I organise and teach into LUT's Entrepreneurship Policy and Enterprise Promotion (6 ECTS) masters-level course and the Entrepreneurship for Academics (6 ECTS) course for doctoral students. I think that the more I understand entrepreneurship education, the more entrepreneurial my teaching practices become.

\section{My Teaching Aim}

My aim is to facilitate participants to reflect on and understand what entrepreneurship and entrepreneurship education is all about and then, based on this broader understanding, let them decide whether one or both of them have something to offer.

As my teaching philosophy is slow, lazy and stupid, I try to motivate the students (participants) to be the active part - given they are the ones to come up with ideas and solutions through the active learning process. For me, it is not about teaching, it should be all about learning.

\section{Getting into EE}

It all started in a national project a long, long time ago and I got immediately carried away; I was hooked! To begin with, I was assigned to participate on that project, and once I learned what EE was all about it was crystal clear that this would be my way of teaching, and that this is a phenomenon I was keen to study further. 


\section{My Connection to EE}

I am an entrepreneur and I did my doctoral thesis on entrepreneurship, so I think I have a personal relationship to the phenomenon, both in theory and in practice.

\section{MY APPROACH TO EE}

In the Finnish school context, EE has been part of the national curricula for basic education since 1994, so we should already have good practices and have produced nice results, but I think we still have some challenges to tackle. I think that, as with any teaching or education, it is good when it meets its goals. However, according to our studies, the challenge in our context is that teachers very seldom set any goals for their EE - nor plan how to put EE into practice. Therefore, I think EE is good when the target audience (participants, pupils, students) understands what an entrepreneurial approach means (in life or in teaching) and discovers ways in which to put it into practice.

\section{EE Tools}

I believe that as individuals we are different learners and, because of that, as educators, we should use a wide variety of different learning activities to meet the needs of different learners. Therefore, the more variety there is, the better. In my classes I try to embed gamification elements, quizzes, visitors, roleplaying (drama pedagogy) and, if possible, I try to take the class outside of the classroom to experience the real world out there. Further, I'm a great advocate for flipped-classroom approaches where students are prepared when they come to the classroom and we can use our valuable face-to-face time on discussions, and on trying to understand different elements and the viewpoint one may have on 'the thing' we are aiming to learn at that moment.

\section{Assessing Outcomes}

As mentioned above, I try to embed as many different activities as possible in my teaching; I also try to embed as many different ways as I can of assessing the outcomes. Most often I use self-reflections and learning diaries. I also find it especially valuable when students set goals for their learning at the beginning 
of the course. Then, at the end of the course, they are able to talk about how they did or did not meet their goals. I use a lot of peer evaluation and often use online Moodle tests.

My Role

I think that the reason I was hooked on EE and entrepreneurial ways of teaching is because I personally identify with these approaches, they align well with my sense of identity. While I can see myself becoming more entrepreneurial everyday, I have always been aligned to the experiential learning methods common to EE. However, I think I have become more tolerant, and hopefully I give increasing amounts of time and space to my students/participants - as I believe it is not about my teaching but about creating space so they can find their own ways of learning.

\section{My Challenges}

I think the most time-consuming aspect is connected to using the 'entrepreneur' word. Some find it scary, some do their best to avoid everything related to it and some just could not care less. I have spent hours and hours introducing the concept of EE. Sometimes it is frustrating, I think I must sound like a broken record, yet at other times it has opened great discussions where we all learn a lot. Although EE has been part of the Finnish national curricula for the last 25 years, interestingly we are still discussing the concept. Therefore, there have been a lot of discussions - and sometimes it is frustrating when trying to convince people to open their mind and to try and understand what $\mathrm{EE}$ is all about, before hearing them say, 'it has nothing for me'.

\section{My Satisfaction}

I love to observe students/participants learning something that they find useful for themselves. When I can see in his or her eyes that some learning has taken place, I call this the 'miracle of learning'. It is always very satisfying to get nice feedback afterwards, especially from those who in the beginning were very cautious and hesitant with regard to the 'E' word.

\section{SHARED WISDOM}


The entrepreneurial approach is a key competence that we all need, whether being or becoming an entrepreneur or employed by a company. I think the entrepreneurial way is needed in all aspects of life. The aim of EE is not to create as many new companies as possible but to help potential entrepreneurs to become capable entrepreneurs as soon as possible. In EE, you encourage your students to face uncertainty, to make and change plans, to spot different opportunities and to take a chance - things that they will need in their studies but also after their graduation.

\section{My Development}

I think tolerance and patience is needed. You need to tolerate the risk that students are not interested in putting themselves in the centre to act as the active part of the learning process. Further, they may request 'traditional teaching'. Therefore, you need to be patient and not give up. They will follow, but it may take some time - and once they start learning, it will still take time. Be slow, lazy and stupid.

\section{Lessons Learned}

You need to be patient. It takes time to embed any entrepreneurial approach into your teaching. The entrepreneurial way of teaching is not a shortcut to learning. Furthermore, some find the entrepreneur-related word scary and to be avoided, so you need to understand and tolerate that, and then be patient in trying to clarify what EE is, and what EE is not. 